\title{
Meiotic Divisions in the Microspore Mother-cells of Smilacina racemosa (L.), Desf.
}

\author{
BY
}

\author{
RUTH WOOLERY, \\ Indiana University, Bloomington, Indiana.
}

With Plate XXII and one Figure in the Text.

$\mathrm{B}$ ECAUSE of some remarkable statements made by Lawson ('11 A) concerning 'The Phase of the Nucleus known as Synapsis', material was collected and work on this paper was begun. Cytology has for many years had many questions of dispute among its investigators, but it is only through continued investigation that the whole truth can be known. As has been found, Smilacina racemosa offers a favourable plant for study, as the flowers are borne in rather small, compact racemes, and several stages in the division of the microspore mother-cells may be found in one flower cluster, the older ones being at the base and the younger at the apex. McAllister ('13) used this plant for his study, but the species of Smilacina used by Lawson ('I1 A and '12) was not indicated.

\section{Material and METHOD.}

Materials for this investigation were collected from the west side of a deep ravine north-east of Bloomington, Indiana, in the latter part of April and first of May in the years 1912 and I9I3. The strong chrom-acetic solution and the stronger Flemming's chrom-osmic-acetic solutions were used in fixing the material. Whole racemes, or portions of racemes, were embedded in paraffin, and sections were prepared varying in thickness from 5 to 15 microns. Preparations were stained in Haidenhain's iron-alumhaematoxylin and in the regular triple stain, using orange $G$ in aqueous solution or as a saturated solution in clove oil. Especially good preparations, showing metaphase and closely-related phases, were secured by using on material fixed in chrom-acetic a solution of gentian violet and clove oil, as suggested in the laboratory by F. L. Pickett. ${ }^{1}$

I A supermaturated solution of gentian violet in clove oil is prepared by adding to a saturated solution of the stain in absolute alcohol an equal volume of clove oil and allowing the mixtore to stand in an open dish at room temperature until all the alcohol has evaporated. The resulting solution is then filtered through paper. After the safranin has been washed from the sections

[Annals of Botany, Vol. XXIX. No. CXVI. October, 1015.] 
As an aid in determining the true form and arrangement of chromatin in the second contraction, and segmented stages, nuclei were reconstructed in plastina, in order to facilitate the interpretation of the individual chromosomes.

The Smilacina which Lawson ('11 A and '12) used was probably Maianthemum Convallaria, Roth, as described in 'British Flora', fifth edition (1887), Bentham and Hooker, or the same plant as described under Unifolium canadense (Desf.), Green, or Smilacina bifolia, Desf., in Britton and Brown, second edition (I9I3). The plant used for this study is Smilacina racemosa (L.), Desf., as described in Gray's Manual, seventh edition (1908), or the same plant as is described as Vagnera racemosa (L.), Morung, in Britton and Brown, second edition (I9I3).

\section{STATEMENT OF THE PROBLEM.}

An attempt has been made in this investigation to make a very careful study of some of the stages in the meiotic divisions of the pollen mother-cells as found in Smilacina racemosa (L.), Desf. There has been much controversy for several years about some phases of cell activity, and, as Farmer ('12) says, 'there is still room for more light'.

The questions of the identity of the chromosomes throughout meiosis and of the behaviour of chromatin threads previous to and during synapsis have been much discussed in cytological literature, and there is still much diversity of opinion in regard to these questions. Among the other questions with which this paper deals are: the character of the synaptic ball, its position and relation to the size of the nuclear cavity, the nature of the chromatin thread after synapsis, during the spireme stage, and in the second contraction, the manner in which the thread segments, and the formation of the bivalent chromosomes.

Resting Stage. During the so-called resting stage the chromatin granules are arranged irregularly on fine linin threads throughout the nuclear cavity, giving the appearance of a network. The granules are more or less irregular in size, shape, and form. The appearance of a network is, no doubt, partly due to the overlacing of threads, as suggested by Lawson ('11 A), but there seem to be more crossed threads than there would be were this entirely the case. The fact that some portions of the fine linin thread

to just the intensity wanted in the finished preparation, the slide should be rinsed harriedly with absolute alcohol and then covered with the clove oil violet. The vlolet should be allowed to act 20 minates to 3 hours, although in some cases staining for 6 hours has given good results. It is then washed off with benzole or xylol and replaced with clove oil orange $G$. If staining of walls is not pranted, final differentintion may be secured by using pare clove oil after 10 to is minutes' use of the orange $G$ solution. It has been found well to remove the clove oil orange $G$ completely with flowing benzole or xylol and to mont the specimen from that medium. It is essential that no alcohol be allowed to çome in contact with the sections after the nse of the clove oil violet. 
seem to be drawn in towards the chromatin granules as nuclear activity proceeds would also indicate that the network arrangement is not merely a fanciful one. There is nothing to indicate that there is a certain fixed number of threads in the resting stage, corresponding to the diploid number of chromosomes as stated by Lawson ('11 A and '12). Very few free ends were seen in nuclei showing this stage, and it would be impossible to count such individual threads if they were present as such in this stage (Figs. I and 2). The number of chromatin granules greatly exceeds the number of chromosomes in any stage of the division; so there is nothing in Smilacina racemosa to indicate that each chromatin mass is a prochromosome, as is claimed by several authors and as emphasized by Stout ('12) for Carex aquatilis. If the chromosomes do retain their identity throughout the resting stage, this identity is, at least, not recognizable at this stage.

Lawson ('11 A and '12) and McAllister ('13) show portions of the chromatin thread pairing during these early stages. Figs. I, 2, 3, 4, and 5 , Pl. XXII, of my preparations show similar stages to those figured by Lawson and McAllister, but in such nuclei, where there are so many crossings of the threads, or where the nuclear contents are in such a finely divided condition, it does not seem to be of any special significance that one portion of the thread should run along parallel to another portion for a short distance. It does not necessarily follow that there is any special relation existing between them. The irregularly shaped chromatin granules fuse later and finally form a smooth-edged thread. The fact that a few of the granules may fuse side by side does not necessarily establish the conclusion that there is a general side-by-side pairing throughout the whole nucleus, and, if such a phenomenon were characteristic of this stage, it would appear more often and in greater regularity. From the conditions as seen during this investigation, it is not possible to agree with Lawson ('11 A) that 'the chromatin threads are undoubtedly double from the beginning', nor that a definite pairing of threads takes place at this stage, nor that ' the developing spireme was not composed of a single continuous thread, but of a number of double threads, and the number corresponds with the diploid number of chromosomes . . . which become differentiated later'. McAllister maintains that there is no chromatin aggregation into prochromosomes.

As to the units which go together to make up the chromatin thread, it is hard to identify them. We cannot recognize the different hereditary characters which develop in the mature individual, in the nuclei of the spore mother-cells, and we cannot say with much degree of certainty that it is thus or so. A mature individual has too many characteristics for each of them to be bound up in a separate chromosome, and this is one argument (Farmer '07) given for the chromomere as the unit. The colloidal nature of the chromatin thread makes it hard to differentiate portions of the thread into units, when they are shifting or changing appearance as much as the 
granules change in the chromatin thread. Lawson ('12) says that 'although threads may appear vacuolated, granular, or even beaded, they are composed of uniform material'. As the nucleus prepares for the activity of the division to follow, the lumps in the thread appear to become somewhat larger and to elongate so that each joins with its neighbours (Fig. 3).

Some of the thin linin threads which appeared to stretch across to other portions of the chromatin now appear to be drawn in and to help make the thread appear somewhat wider. Fig. 4 is taken from a section cut 5 microns in thickness and portions of the chromatin network are shown. Fig. 5 is a portion of another nucleus in which the chromatin granules are more evenly distributed along the thread, and it has more the appearance of a continuous thread than of a network. In some places portions of the thread lie almost parallel with each other. In one place two portions seem to be joined together by a slight attenuation of one thread, but it cannot be said with certainty that this indicates any pairing which will persist. The chromatin thread here is becoming slightly contracted.

The mother-cells, during the resting stage, are closely packed together and have thin walls and uniformly dense cytoplasm. From one to three or four nucleoli are seen irregularly placed in the nucleus, in among the irregular chromatin thread. The nuclear membrane appears as a sharp line separating cytoplasm from nuclear contents. The enlargement of the núclear cavity, which takes place about this time, is doubtless coincident with an increase in the amount of containing fluid as Lawson (' $11 \mathrm{~A}$ and ' 12 ) shows, but there is also, at this time and following it, a shortening and thickening of threads and a contraction which results in the diminution of the chromatin mass.

Synapsis. Measurements were taken of nuclei in the resting, synaptic, spireme, and segmented stages, and the results that were found do not substantiate Lawson's theory ('11 A and '12) that the nuclear cavity enlarges but the chromatin mass remains stationary in volume. The measurements show an increase in the size of the nuclear cavity just preceding and during synapsis, which size remains relatively stationary during the spireme and segmented stages; but unquestionably a decrcase in the size of the chromatin mass is found in synapsis. In taking measurements nuclei were chosen at random, care only being taken that the section should be cut as nearly through the centre of the nucleus as possible. Of the nuclei measured, the average for the resting stage was 16 microns by 14 microns. Nuclei in the synaptic state were measured, with an average size of 23 microns by 18 microns, while the chromatin mass from these same nuclei gave an average measurement of 13 microns by so microns. The two dimensions denote the greatest and shortest diameters of each nucleus or mass. The measurements of the nuclei in spireme and segmented stages show sizes tallying with the measurements of the nuclear cavities of nuclei with chromatin in 
synaptic state. These results show that there is an increase in the volume of the nuclear cavity, and also a decrease in the space which the chromatin mass occupies. Figs. 5, 6, 7, and 8 show progressive steps in the arrangement of the chromatin to form the synaptic mass.

Many cases were found in which the mass of contracting or contracted chromatin threads was fastened or swung to the nuclear membrane by fine strands as shown by Mottier ('07) and others, and is here shown in Figs. 6, 7 , and 8 . The position of the synaptic mass in the nuclear cavity seems to háve no special significance, as the ball is located differently in different cells of the same loculus. The most common position was found to be close to one side of the cavity (Fig. 8), but other angles of sectioning would of course show masses in the same relative positions differently. There is no special position relative to gravity.

Fig. 6 shows the chromatin mass drawn away from the nuclear membrane, and its position is probably due partly to the expansion of the membrane, and partly to the contraction of the chromatin contents. Here the chromatin appears as lumpy portions of threads, which, when viewed from the standpoint of the stages preceding it, are due to the running together of some of the granules and the contraction of the whole thread. Some portions of the thread seem thicker than others, as McAllister ('18) has found, but no real pairing is apparent. Fig. 7 shows a slightly later stage, in which the chromatin appears balled up around the large nucleolus, and the threads are becoming more uniform in thickness. Some portions of the thread are drawn out from the mass by the strands which connect them to the nuclear membrane. Cut ends are shown where the knife has sectioned what were probably loops extending from the mass. These loops are not made up of double threads. Figs. II and I2 show tangential sections of late synaptic stages, and show loops and places where portions of the thread run along parallel to each other or in close proximation. They appear, however, as separate portions of thread rather than as portions of a double or paired thread. Figs. 9 and 10 were drawn from cells in the same loculus and side by side, with cell-walls not yet separated. They are typical stages showing the chromatin coming out of synapsis, but show nothing that indicates any pairing or previous pairing of threads. Fig. I3 shows a slightly older stage, and was found in a loculus with other nuclei in which the spireme threads were evenly distributed.

It cannot be said with certainty that there is a fusion of maternal and paternal chromatin in the synaptic state, because there is no means of distinguishing between parts of the chromatin on any such basis. Because of the fact that we can see the partial contraction of the chromatin into threadlike portions before they enter the synaptic state, and as tangential views show this condition persisting, there seems to be no indication that synapsis is other than a contraction of the chromatin and a subsequent shortening 


\section{Woolery.-Meiolic Divisions in the Microspore}

and thickening of the threads to make a spireme of uniform thickness. Lawson ('12) maintains that there is a shortening and thickening of the spireme threads, but he does not show the chromatin aggregated into a tight synaptic ball. It is difficult to say just what position the chromatin units take, if there are any which are truly such. The significance of any special arrangements which may occur is also difficult to determine. It is not until later stages that true splits are seen in the chromatin thread (Figs. 16 and 17 ).

Figs. II and I2 show portions of thread which are much narrower than in most nuclei at this stage. Anthers from different flowers, however, show this difference in width of threads, especially noticeable at this stage. (Compare Figs. 9 and Io with Figs. II and 12.)

Spireme. As the chromatin thread comes out of the synaptic state it is seen to have a greater diamcter and is more uniform in thickness than the thread as it began to contract. This shortening and thickening has resulted in one continuous spireme. Sometimes the thread appears lumpy, but when it is evenly distributed throughout the nucleus, it appears as a smooth thread of uniform thickness (Fig. I4). Fig. I3 shows a slightly younger stage from a nucleus which was cut tangentially and was found in a loculus in which the nuclei all showed threads not yet fully untangled from the synaptic condition. The chromatin thread winds in and out through the nuclear cavity in a tortuous manner.

There has been much discussion as to whether the nucleus at this stage contains one continuous chromatin thread or as many threads as the diploid number of chromosomes. Lawson ('11 A) identified individual chromosomes throughout all the prophases of the nuclei of Smilacina, while McAllister ('13) finds a continuous spireme in Smilacina racemosa. This study shows the thread to be continuous, as has been found by McAllister ('13), Mottier (07, '09, '14), and others. Several hundred nuclei were examined and studied under the best conditions to determine this point, and a model was made and sectioned to aid in the determination. Ends can be seen in abundance in sections of the nucleus showing spireme threads, but when it is possible to examine a whole nucleus or most of a whole one in one section the number of ends diminishes, so that it cannot be that there are as many threads as there are chromosomes appearing later. Fig. I4 shows almost a whole nucleus, and all the ends seen were carefully focused upon and appeared in such a plane that they surely were, at least most of them, cut ends. In Fig. I4 ten ends show, but this number is much too few if twenty-four is the haploid number of chromosomes for the plant. Long portions of continuous thread may also be traced through the nucleus.

Loops appear to reach out to the nuclear membrane of some nuclei in the spireme stage, and some portions of thread run along close to the membrane for short distances, indicating that there are probably some connexions existing between the thread and the membrane. Such stages as 
are shown in Figs. 6, 7,8, 9, and IO, and those shown in later stages (Figs. I 5 and 16 ), would indicate that portions of the threads are attached to the nuclear membrane throughout a greater part of the prophases of the first division.

Some nuclei at this stage show jagged spireme threads, but most of the evenly distributed spiremes seem to be of almost uniform thickness. No splits were observed in the spireme at this evenly distributed stage, and not until later was any longitudinal split observed (Figs. I6 and I7).

Second Contraction. From the spireme stage the chromatin thread undergoes a second contraction, as has been observed by many observers (Fig. I4). The thread, in its shortening process, is drawn up in a tangled mass near the centre of the nucleus (Fig. I6). Radiating loops may be seen extending from the central mass and fastened to the nuclear membrane. Mottier ( 07 ) found such a condition especially common in Lilium. As Lewis ('08) found in Pinus, in Smilacina racemosa 'the spireme often presents an extremely jagged structure just before cross-segmentation'. In some nuclei attenuations from portions of the bivalent chromosomes may be seen after segmentation (Fig. I8). Many nuclei showed much more jagged threads than are figured in the drawings accompanying this paper. During this stage and later the chromatin thread appears split (Figs. I6 and 17 ), and this fission is undoubtedly in preparation for the splitting of the chromosomes, which brings about the division of chromatin in the second division or formation of the granddaughter cells.

Segmented. Cross-segmentation of the spireme thread takes place while the spireme is in the state of second contraction. The thread may break near the periphery of the mass or nearer the centre, but it segments, and the bivalent chromosomes result from the approximation of two segmented portions of thread (Figs. I7, I8, I9, and 20). These findings agree with the descriptions of this stage as given by Farmer ('05), by Mottier ('07, '09, and '14), Lewis ('08), McAllister ('13), and several other cytologists, in contrast with those who maintain the view of parasynapsis taking place in the synaptic phase (Lawson ' $11 \mathrm{~A}$ and '12, Stout '12, and others). The spireme in Smilacina racemosa, however, is continuous or approximately so, and cross-segmentation takes place during the phase of the shortening and thickening of the thread just at the close of the second contraction stage. Lawson ('12) contends for the lateral pairing of the chromosomes which have retained their identity throughout the prophases, but states that the pairing is only temporary, so that it is not significant whether this pairing is lateral or end to end. We do not know just what is the true significance of this association, but it is in preparation for the reduction which takes place in the formation of the daughter nuclei. The point of real significance is whether or not there is a pairing of the somatic chromosomes in the earlier prophases which brings about a union of maternal and paternal chromatin.

A photograph was taken of one of the plastina models made to aid in 
the determination of the true forms and shapes of chromosomes, and it was found that the photograph bears a striking resemblance to the nucleus as seen in the microscope and as figured with drawing accompanying this paper. (Compare Text-fig. with Fig. I7.)

The bivalent chromosomes which result from cross-segmentation continue to shorten and thicken until they take the form as shown on the spindle plate (Fig. 2I). They can be found assuming all the different shapes which have been described for them and in many different arrange-

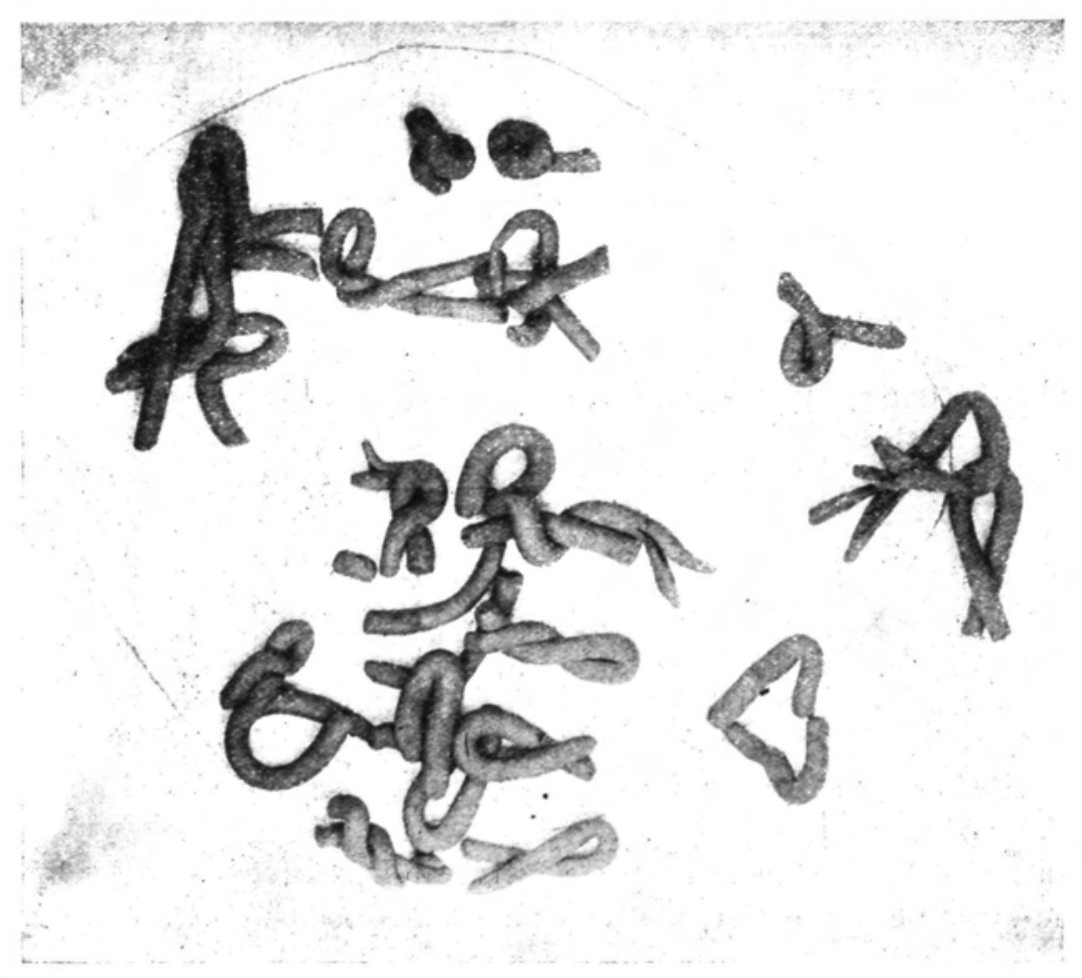

Text-FIG. Photograph of plastina model of the same nucleus from which Fig. I 7 on Pl. XXII was drawn.

ments. Figs. 16 to 20 show different shapes in which the chromosomes appear during this segmented stage. Some nuclei show bivalents of different lengths and widths (Figs. 17, 18, 19, and 20). Fig. 18 shows one bivalent which is bent back upon itself. Fig. I 9 shows one portion of the segmented thread which is curved twice, but the limbs are not yet tightly wound about each other (Figs. I7 and I8), while others remain in ring-shaped forms.

Farmer and Digby ('13) have discussed the possible significance of the different sizes of chromosomes and the constancy of this variance in any one 
Downloaded from https://academic.oup.com/aob/article-abstract/os-29/4/471/226502

by University of Durham user

on 22 March 2018 
Annals of Botany
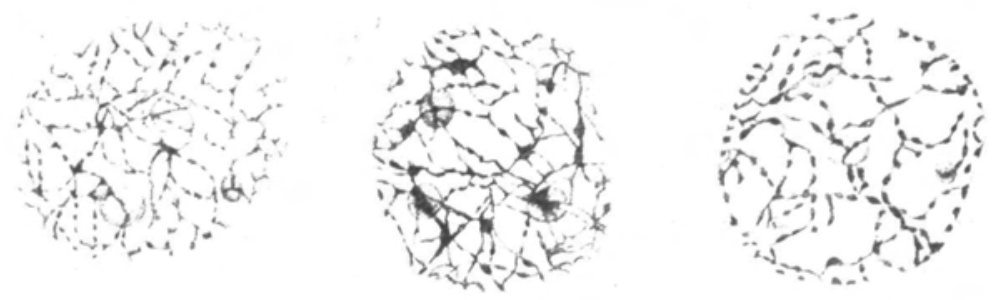

2

3
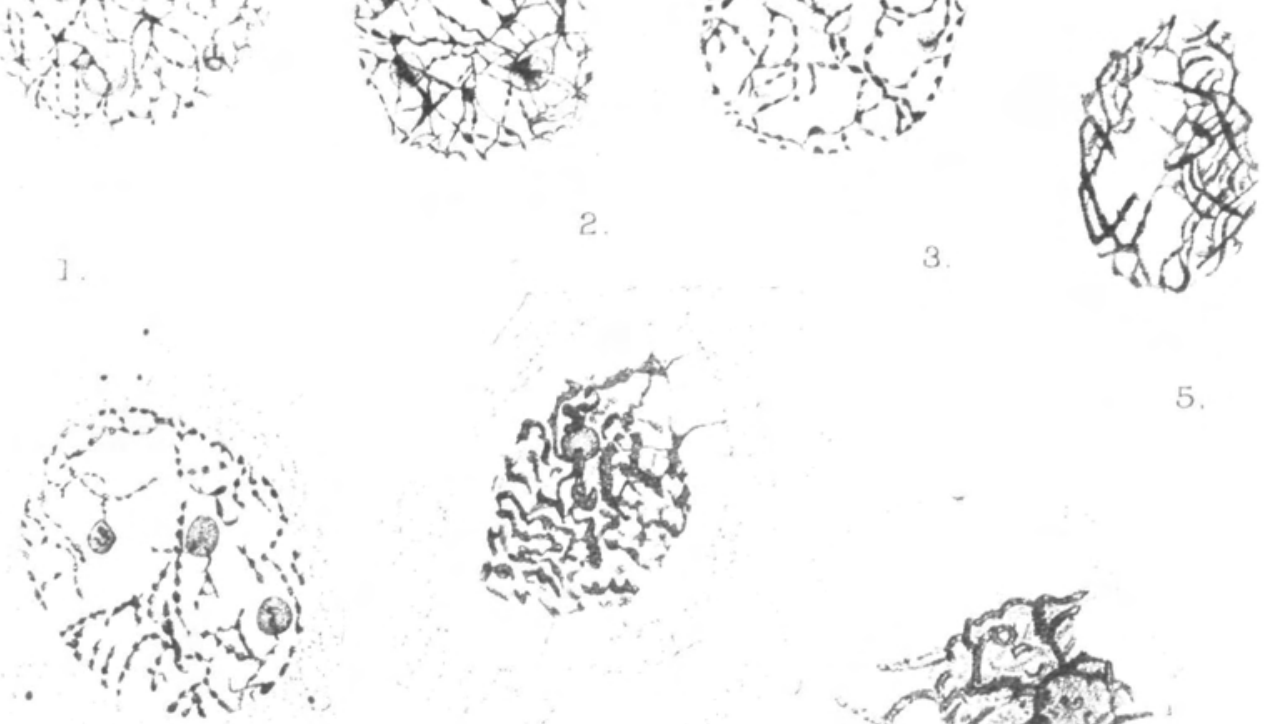

6.
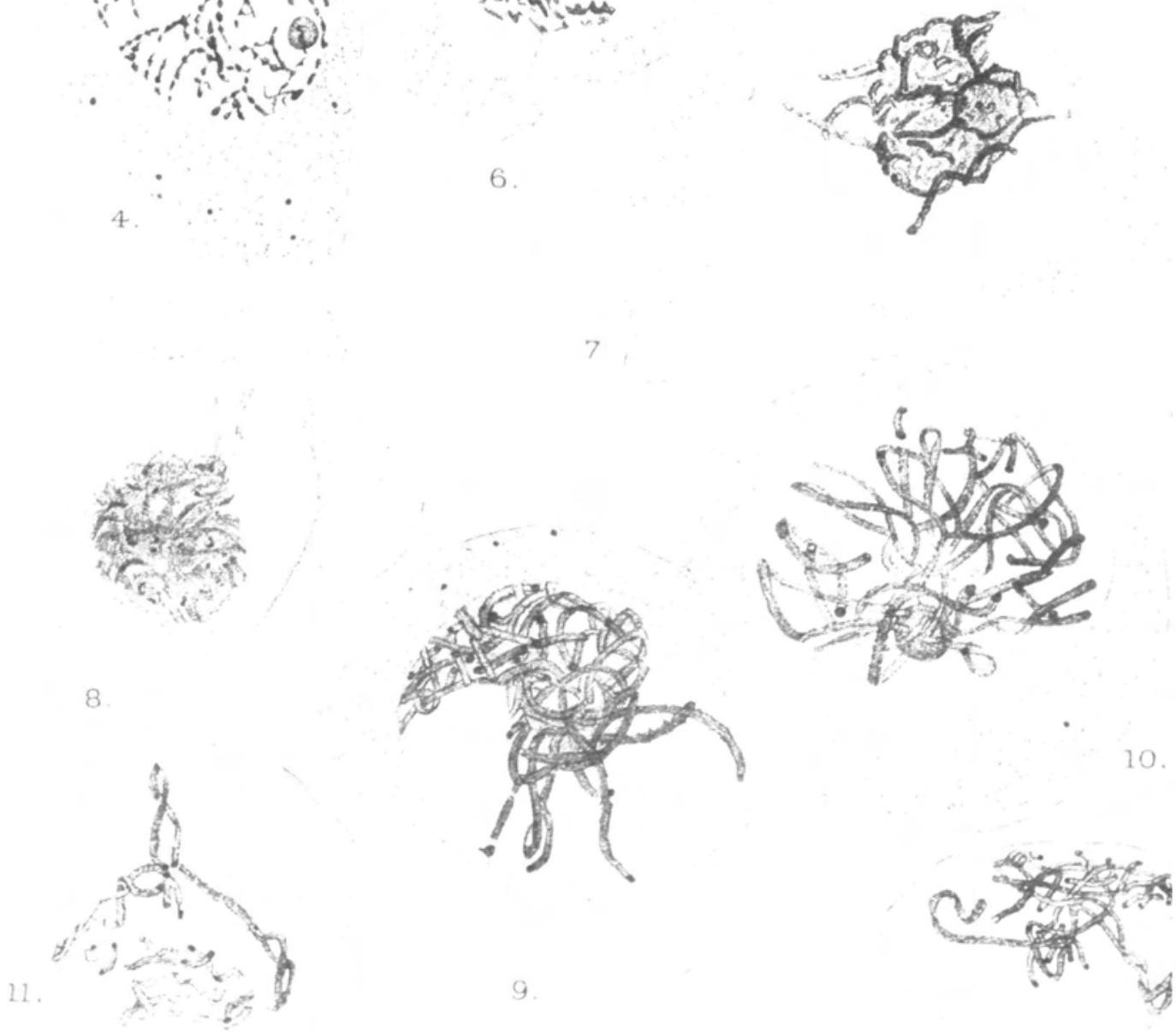

H...det. 


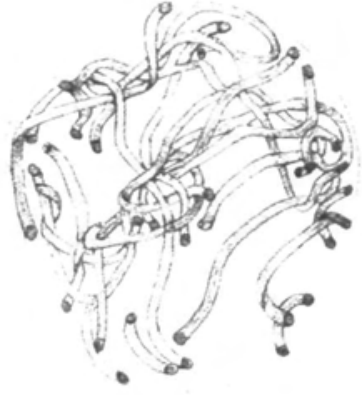

13.
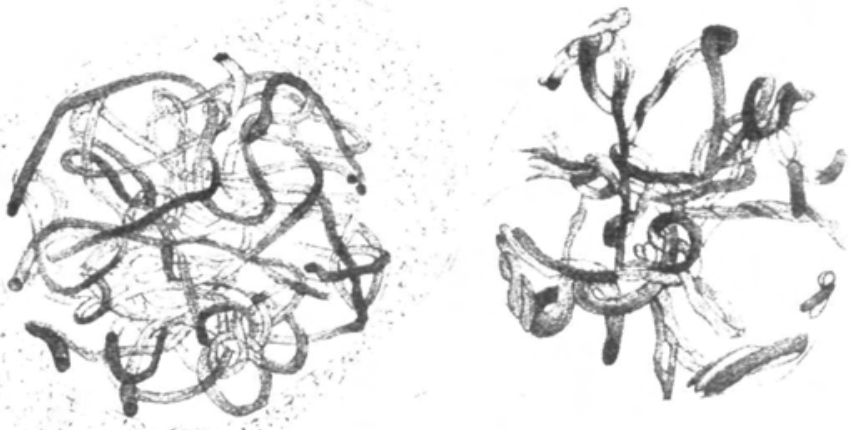

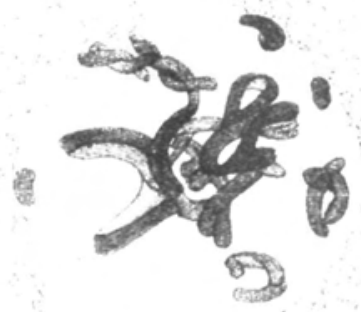

14.
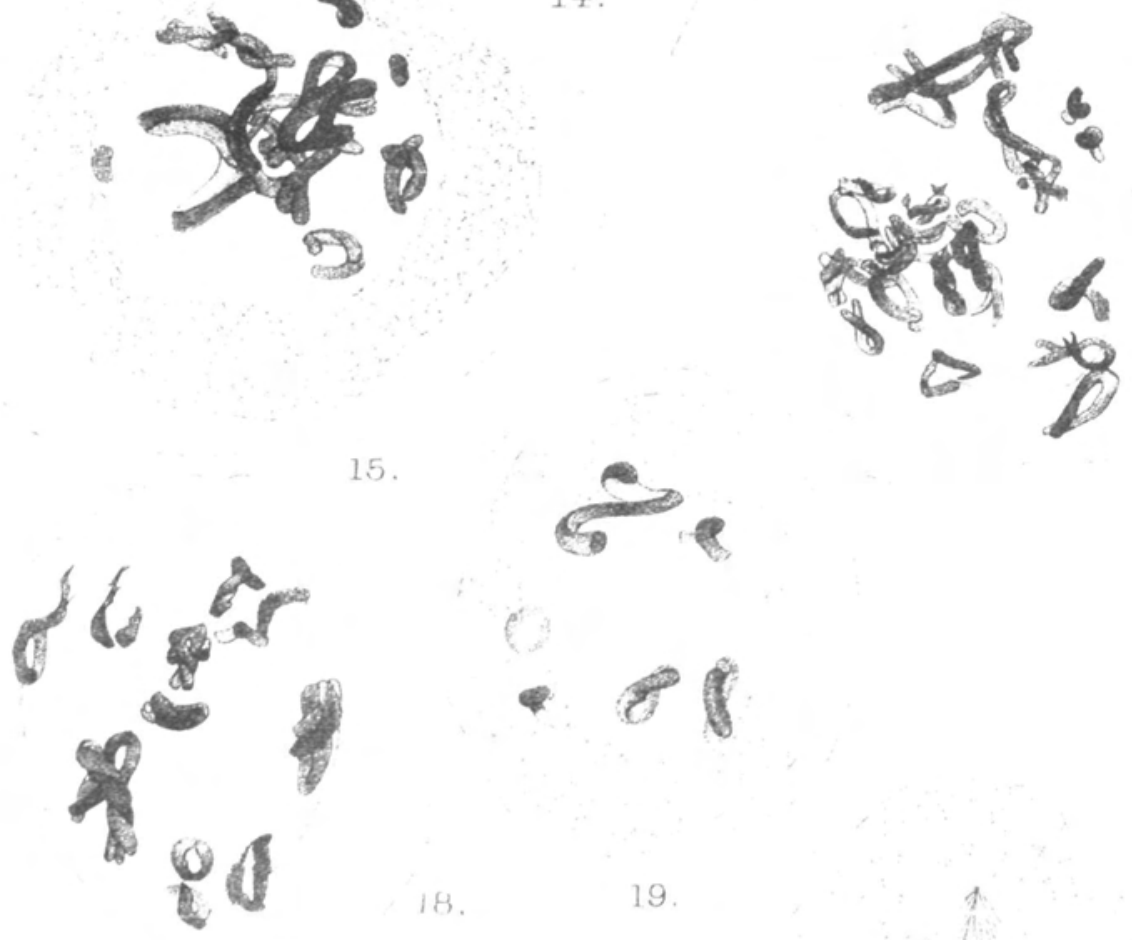

15.
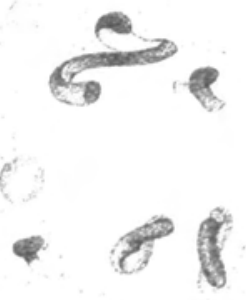

18.

19.
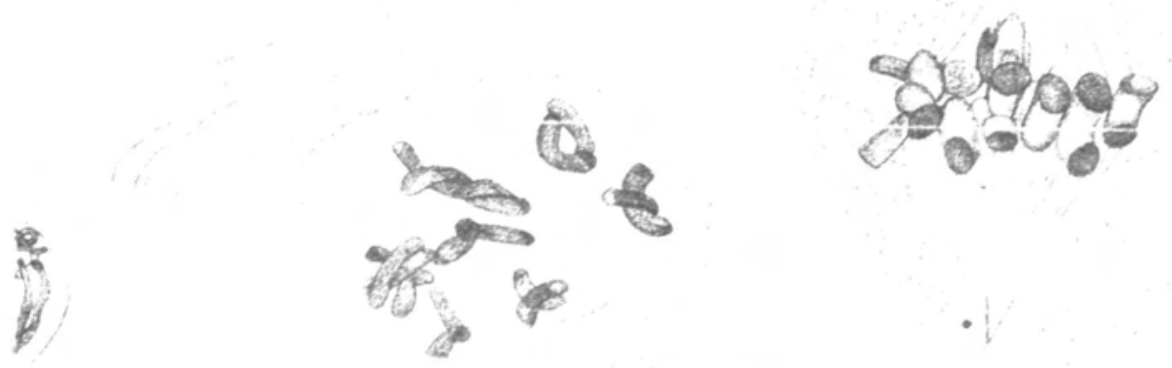
Downloaded from https://academic.oup.com/aob/article-abstract/os-29/4/471/226502

by University of Durham user

on 22 March 2018 
species, and attach no special significance to this difference in size, as some cytologists do. The sizes do not remain constant throughout any one species; so no hereditary significance can be attached to these differences. In Smilacina racemosa different sizes of chromosomes appear in the segmented stage and on the spindle plate, but the differences in size and shape are not constant: that is, a chromosome of certain size or shape cannot be found in all nuclei at this stage, and the chromosomes are constantly changing size as they contract.

Lawson ('11 A) gives 20 as the probable haploid number of chromosomes in the Smilacina with which he worked, but later (Lawson'12) changed the number to I4. McAllister ('13) gave 24 for the haploid number in Smilacina racemosa. The findings in this investigation agree more nearly with McAllister, the countings showing from 20 to 24 chromosomes.

The cell-walls are thin in the resting stage, but, as the cells round off during and immediately after the synaptic stage, they begin to thicken, and in the segmented and spindle stages a very thick special wall surrounds the pollen mother-cells. (Compare Figs. I, 7, 1 4, 15, 20, and 21.)

Spindle. The chromatin thread undergoes a continuous shortening and thickening throughout the prophases, and, when the chromosomes. appear on the spindle in the metaphase, they are very short and thick (Fig. 21): There is no indication, in the nuclei examined in this investigation, that the spindle fibres are formed by a gradual contraction of the nuclear membrane, a closing in around each chromosome and a subsequent tension resulting in the cytoplasm forming fibres, as advocated by Lawson ('1l B) for the microspore mother-cells of Disporum gladiolus, Yucca, Hedera, for the vegetative cells in the root-tip of Allium, and later for the microspore mother-cells of Smilacina. The difficulties involved in such a process have been discussed by Farmer ('12 and '13), and further discussion seems useless here. In no case was the nuclear membrane in Smilacina racemosa seen to contract around the chromosomes in such a manner as Lawson described. The spindle fibres, rather, appear to be formed in the manner described by Mottier ('97) and others. It was often found that in the same loculus were nuclei in the typical segmented stage and other nuclei with fully developed bipolar spindles. In some nuclei the nuclear membrane appeared to be partly broken down, in some fibres were appearing, in others portions of the membrane persisted as fibres appeared, while in still others the membrane was entirely broken down and the chromosomes were arranged on the spindle in the typical metaphase condition.

\section{SUMMARY.}

I. The microspore mother-cells of Smilacina racemosa have the nuclear contents in a finely divided state during the resting stage, with irregularly shaped granules held in the meshes of a fine linin network. 
2. There is no lateral pairing of the chromatin threads during this or the synaptic stage. Neither does the chromatin content consist of a number of chromatin threads which equals the diploid number of chromosomes for the species.

3. Synapsis is a stage which is characterized by a very general contraction of the nuclear contents into a tight ball, usually lying at one side of the cavity, and an increase in the size of the nuclear cavity.

4. The contents of the nucleus are often connected with the nuclear membrane by fine strands.

5. The mass of chromatin threads untangles, and a continuous spireme of uniform diameter is evenly distributed throughout the nuclear cavity. Connexions between the chromatin thread and the nuclear membrane still persist.

6. Immediately after this state of the evenly distributed spireme follows a second contraction or central entangling of the spireme with loops radiating from the centre to the periphery. Longitudinal splits may be seen in the thread at this time.

7. Cross-segmentation of the chromatin thread takes place either at the centre or near the periphery of the tangle, and a lateral approximation of the limbs of loops or of separate portions of chromatin thread takes place to form the bivalent chromosomes.

8. Fibres appear around the nucleus, the membrane breaks down, the characteristic bipolar spindle is finally formed, and the bivalent chromosomes are arranged in a plate at the equator of the spindle.

I wish to express my gratitude to Prof. D. M. Mottier for his most helpful suggestions and criticisms during the preparation of this paper.

INDIANA UNIVERSITY.

\section{LITERATURE CITED.}

FARMER, J. B., and MoOre, J. E. S. ('OS) : On the Maiotic Phase (Reduction-division) in Animals and Plants. Quarterly Joumal of Mieroscopical Science, vol. xlviii, Ig05, Part IV.

FARmer, J. B. ('07): The Structural Constituents of the Nacleus and their relation to the Organization of the Individual. Croonian Lecture, Proc. Roy. Soc. London, Series B, vol. lxxix, I9o7, p. 534 .

('12): Naclear Osmosis and its assumed relation to Nuclear Division. The New Phytologist, vol. xi, 1912, pp. r 39-44. Pp. $22-8$.

Faraer, J. B., and DigBy, L. ('13): On Dimensions of Chromosomes considered in relation to Phylogeny. Philosophical Transactions of Royal Society of London, Series B, vol. ccv, 1913 , Pp. I-25.

Lawson, A. Anstruther ('11 A): The Phase of the Nucleus known as Synapsis. Transactions Royal Society of Edinbargh, vol. xlvii, Part III, IgI I, Pp. 591-604 


\section{Mother-cells of Smilacina racemosa (L.), Desf.}

Lawson, A. Anstruther ('11 в) : Nuclear Osmosib as a Factor in Mitosis. Transactions Royal Society of Edinburgb, vol. xlviii, Part I, 19I 1, pp. 137-6I.

('12): A Study in Chromosome Reduction. Transactions Royal Society of Edinturgh, vol. xlviii, Part UI, 1912, pp. 601-27.

Lewis, I. M. ('08): The Behaviour of the Chromosomes in Pirus and Thaja. Ann. of Bot., vol. xxii, No. lruxviii, 1908, pp. 529-56.

McAllister, Frederick (13): On the Cytology and Embryology of Smilacina racemosa. Transactions of the Wisconsin Academy of Sciences, Arts and Letters, vol, xviii, Part I, 1913 , pp. 599-660.

Motrier, D. M. ('97) : Beiträge zur Kenntniss der Kernteilung in den Pollenmatterzellen einiger Dikotylen und Monokotylen. Jahrb. f. wiss. Bot., Band xxx, Heft 2, 1897, pp, 169-204. - ('07): The Development of the Heterolypic Chromosomes in Pollen Mother-cells. Ann. of Bot., vol. xui, No. lsuriii, 1907, pp. 304-47.

('09) : Prophases of Heterotypic Mitosis in the Embryo-sac Mother-cells of Liliuns. Ann. of Bot., vol. xriii, No. xci, I909, pp. 343-52.

('14) : Mitosis in Pollen Mother-cells of Acer regrundo, Lu, and Stapkylea trifolia, L. Ann. of Bot., vol. Ixviii, No. cir, 1914, pp. I I 5-33.

Stout, ArLow Burdette ('12): The Individuality of the Chromosomes and their Serial Arrangement in Carex aquatilis. Contributions from New York Botanical Garden, No. I 50. Archiv tür Zellforschang, vol. ix, 1912, Pp. 114-40, P1. 1 1, 12, 3 D.

\section{EXPLANATION OF PLATE XXII.}

Illastrating Miss Woolery's paper on Meiotic Divisions in the Microspore Mother-cells of Smilacina racemosa (Lo), Desf.

All figures were drawn from sections with the aid of the Abbe camera lacida with Zeiss apochromatic immersion $2 \mathrm{~mm}$. apert. $1_{4}^{\circ}$, and compensating ocular 12. Magnification about 1750 to 1800 .

Fig. I. Resting nucleus of the microspore mother-cell, showing typical structure of nucleus and cytoplasm.

Fig. 2. Resting nucleas with slightly larger chromatin granules. Some portions of threads lying parallel.

Fig. 3. Tangential view, showing larger lumps of chromatin. Some portions of the linin thread have been drawn in.

Fig. 4. Tangential view of stage similar to Figs. 1, 2, and 3.

Fig. 5. Chromatin thread beginning to contract and to become more uniform in diameter.

Fig. 6. Enlargement of nuclear cavity and contraction of nuclear contents. Strands are connecting chromatin with the nuclear membrane.

Fig. 7. Chromatin contents much contracted and nuclear cavity much enlarged. Strands extend from chromatin to nuclear membrane. The cell-wall is somewhat thickened.

Fig. 8. A typical tight synaptic ball.

Fig. 9. Nucleus, showing antangling of synaptic ball, with thread of almost uniform thickness.

Fig. 10. Slightly older stage. Sereral cut ends are visible. Figs, 9 and to are drawn from adjoining nuclei in the same loculus,

Fig. 11. Tangential view of nucleas just after synapsis, showing looping and twisting of thread.

Fig. 1 2. Tangential view similar to Fig. 11. The thread is much narrower than in most nuclei at this stage.

Fig. 13. Untangling not yet complete. Many cut ends are shown. Thread of uniform diameter.

Fig. 14. Typical spireme stage. Relatively few cut ends to be found. 


\section{Woolery.-Microspore Mother-cells of Smilacina racemosa.}

Fig. 15. Segmentation into bivalent chromosomes has just taken place. Some bivalents are formed by approximation of limbs of loops and some by the approximation of the separate chromosomes.

Fig. 16. Second contraction stage. Longitudinal splits of the thread are appearing. Looping and twisting of threads is taking place. p. 8.)

Fig. I7. Bivalent chromosomes in various shapes and forms. (Cf. photograph of model on

Fig. I 8. Segmented stage. The bivalent chromosomes are of different sizes. One chromosome of each of three bivalents is drawn out as if by some tension.

Fig. 19. Bivalent chromosomes, one with two loops bat with halves not yet twisted around esch other.

Fig. 20. Various shapes of bivalent chromosomes.

Fig. 21. A typical bipolar spindle showing metaphase. The cell-wall is very thick. 